\title{
Pattern of adverse drug reactions in rural tertiary care medical college and hospital of Himachal Pradesh: A retrospective observational study
}

\author{
Himani Prajapati ${ }^{1}$, Dinesh Kansal ${ }^{2, *}$, Usha K.Chaudhary ${ }^{3}$ \\ ${ }^{1}$ Patient Safety Associate, ${ }^{2}$ Professor and HOD, Dept. of Pharmacology, ${ }^{3}$ Associate Professor, Dept. of Anaesthesia, Dr. RPGMC \\ Tanda, Kangra, Himachal Pradesh, India \\ *Corresponding Author: \\ E-mail: Dinesh.Kansal56@gmail.com
}

\begin{abstract}
Introduction: Adverse events can lead to admission in hospital, prolongation of hospitalization, increase in investigations as well as treatment costs, deformities, danger to life and even death.

Objective: The aim of this study was to conduct adverse drug reactions (ADRs) monitoring in various departments of a tertiary care teaching hospital.

Methods: A retrospective observational study was conducted on ADRs reported in adverse drug monitoring center of our hospital from April, 2016 to December, 2016. Data such as age, gender, diagnosis, drug intake, types of ADRs, treatment and outcome of the reactions were collected. Each reported patient was assessed individually. Causality assessment was done on Naranjo's probability scale. Modified Hartwig's criteria were used to assess the severity of ADRs.

Results: A total of 173 reports were studied. 65 (38\%) patients were males and 108 (62\%) were females. The majority of ADRs were due to cancer chemotherapy agents in 87 (50\%), followed by anti-tubercular drugs in 22(13\%), antimicrobial agents in 22 $(13 \%)$ and anti-retroviral drugs in 16(9\%). Out of total 574 events, 192 (34\%) complaints comprised of gastro-intestinal manifestations. On Naranjo's probability scale, $111(64 \%)$ reactions were probable, $54(31 \%)$ as possible and $8(5 \%)$ as certain. According to Modified Hartwig's criteria 130 (75\%) reactions were mild, 29 (17\%) were moderate and 14(8\%) were severe. Conclusion: Health-care providers will have to do vigilant monitoring and reporting of ADR's.
\end{abstract}

Keywords: Pharmacovigilance, Adverse drug reactions, Chemotherapy, Causality assessment, Tertiary care teaching hospital.

\section{Introduction}

Adverse events can lead to hospitalization, prolonged stay, increase in investigations and treatment cost, birth defects and even death. World Health Organization (WHO) defines ADR as "response to a drug, which is noxious and unintended, and which occurs at doses normally used in man for prophylaxis, diagnosis or therapy of disease, or for the modification of physiological function. ${ }^{1}$ Pharmacovigilance Programme of India (PvPI) 2014 states that $6.7 \%$ of patients have serious adverse events. Similar studies have documented that hospital admissions due to ADR were $3.4 \%$, hospital readmissions were $3.7 \%$, and mortality was $1.8 \% .^{2}$

\section{Materials and Methods}

This was a retrospective observational study conducted for a duration of 6 months, from April 2016 to December 2016 at Dr. Rajendra Prasad Government Medical College and Hospital Kangra at Tanda. ADR details were collected from the Adverse Drug Monitoring Center of the institution. Patient information such as age, gender, diagnosis, drugs prescribed, types of ADR, treatment and outcome of the reaction were collected. Each reported patient was assessed individually. Causality assessment was done based on Naranjo's probability scale. The total score was calculated based on the scale and it was categorized as certain (score >9), probable (score 5-8), and possible (score 1-4). ${ }^{3}$

\section{Results}

Total 173 case reports were studied. Of these males were $65(38 \%)$ and females were 108 (62\%). (Fig.1).

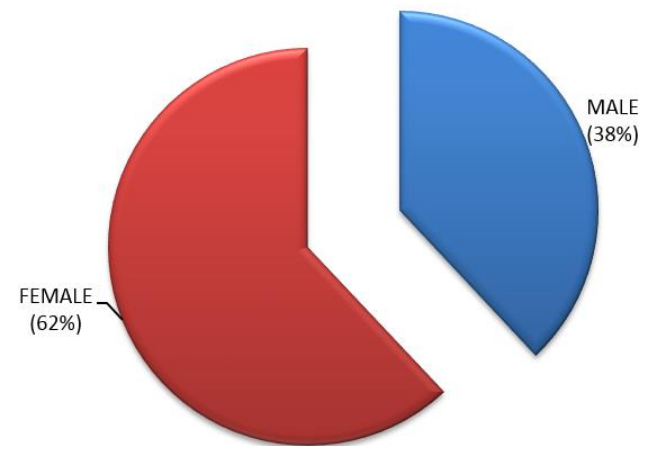

Fig. 1: Gender distribution

Age and Gender Distribution: Most of the patients were in age group of 19 to 80 years (95\%). prevalence of ADR's was more in female population. The mean age of males was $49.15 \pm 16.86$ years and females was $47.58 \pm 15.69$ years. Maximum 71(41\%) patients were from the age group $41-60$ years. (Table 1).

Table 1: Age and gender distribution

\begin{tabular}{|c|c|c|c|}
\hline Age group & Male & Female & Total (173) \\
\hline $1-18$ Yrs & 5 & 3 & $8(4.62 \%)$ \\
\hline $19-40$ Yrs & 14 & 36 & $50(28.90 \%)$ \\
\hline $41-60$ Yrs & 28 & 43 & $71(41.04 \%)$ \\
\hline
\end{tabular}




\begin{tabular}{|l|c|c|c|}
\hline $61-80$ Yrs & 17 & 26 & $43(24.85 \%)$ \\
\hline Above 80 Yrs & 1 & 0 & $1(0.57 \%)$ \\
\hline
\end{tabular}

Drugs responsible for the adverse drug reactions were mostly anticancer drugs $87(50 \%)$, followed by antitubercular drugs $22(13 \%)$, antimicrobial agents 22 (13\%), antiretroviral drugs $16(9 \%)$ and others in 26 (15\%) patients. Others consisted of anti-snakevenom, blood transfusion, anti seizure drugs and NSAIDs. Chemotherapeutic drugs were responsible for most of the adverse drug reaction in 147 (85\%) patients. (Fig. 2).

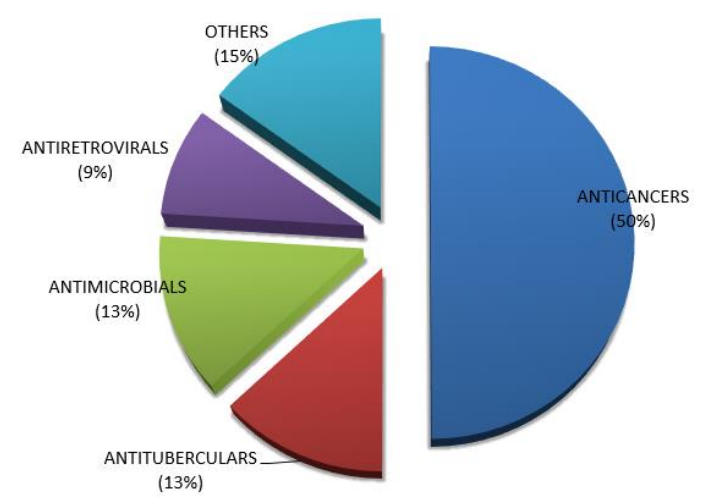

Fig. 2: Drugs responsible for the ADRs

Seriousness of the adverse drug reactions $123(71 \%)$ patients required no hospitalization, followed by hospitalization in $18(10 \%)$, intervention was required in $16(9 \%)$, life threatening events in $7(4 \%)$, disability in $6(4 \%)$ and death in $3(2 \%)$ patients (Fig. 3 ).

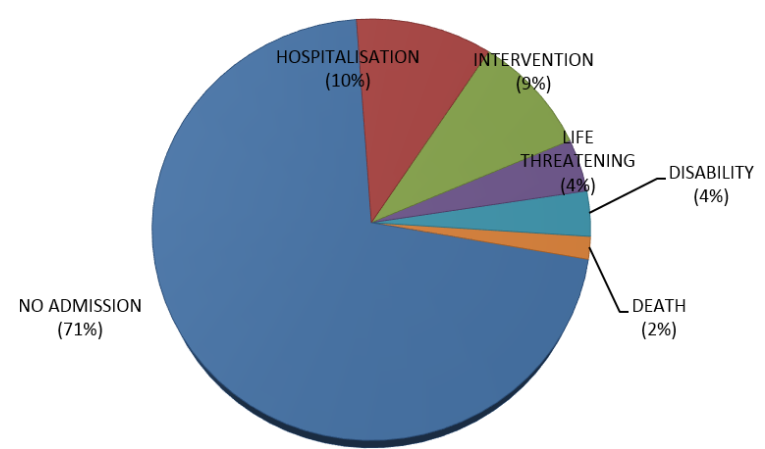

Fig. 3: Seriousness of the ADRs

Severity assessment Adverse drug reactions were mild in $130(75 \%)$, moderate in $29(17 \%)$ and severe in 14 (8\%) (Fig. 4).

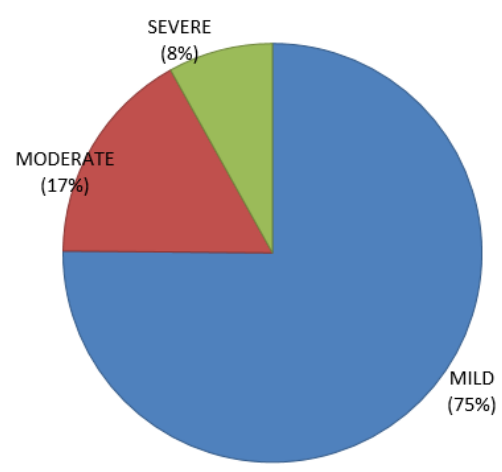

Fig. 4: Severity of ADRs

Causality assessment was probable in 111 (64\%), followed by possible in $54(31 \%)$ and certain in $8(5 \%)$ patients (Fig. 5).

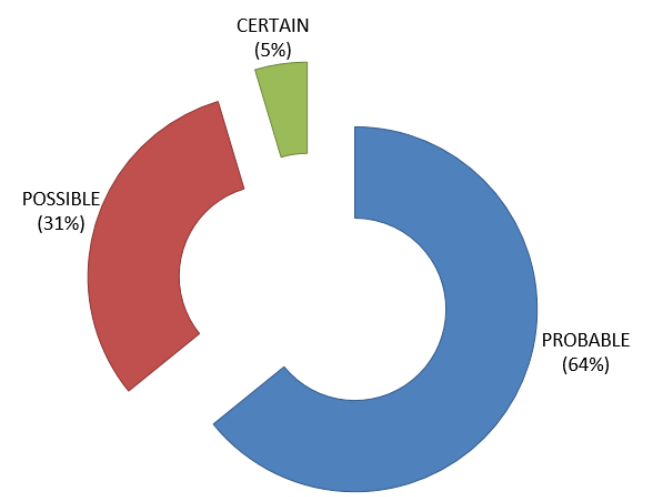

Fig. 5: Causality assessment

Action taken No change in prescription was required in 111 patients $(64 \%)$, followed by drug withdrawal in 54 patients $(31 \%)$ and dose reduction in $8(5 \%)$ patients (Table 2).

Table 2: Action taken after reported adverse drug reactions

\begin{tabular}{|l|c|}
\hline \multicolumn{1}{|c|}{ Action taken } & Number of Patients (173) \\
\hline No change required & $111(64.16 \%)$ \\
\hline Drug withdrawn & $54(31.21 \%)$ \\
\hline Dose reduced & $8(4.62 \%)$ \\
\hline
\end{tabular}

Organ systems involvements in ADR's Out of 574 adverse events reported, most commonly gastrointestinal system was involved in 192 (34\%), followed by nervous system in $132(23 \%)$, skin in 86 $(15 \%)$, eye and ENT in $37(6 \%)$, musculo-skeletal system in $11(2 \%)$, hematological system in $9(2 \%)$, psychiatric symptoms in $8(1 \%)$ and genito-urinary system in 6 (1\%) and others in 93 (16\%) (Fig. 6). 


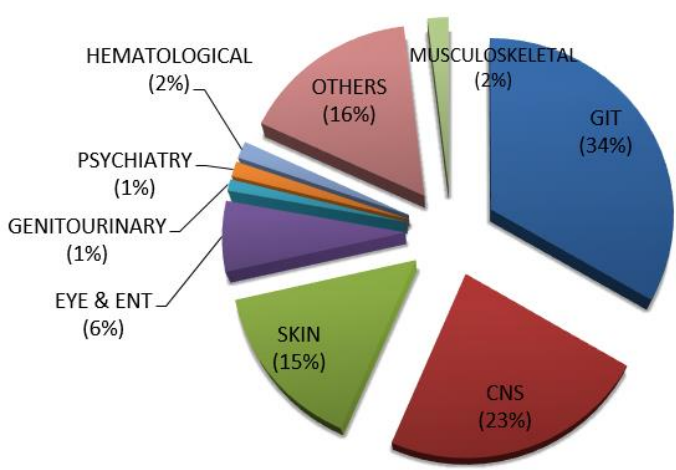

Fig. 6: Organ systems involvements in adverse drug reactions

\section{Discussion}

ADR's are more prevalent among females as compared to males which was similar to study done by Saravanan et al. ${ }^{4}$ Incidence in the female adult population could be explained by the fact that women are more prone to polypharmacy and more sensitivity toward medication. ${ }^{5,6}$

Severity of reactions was similar to a study by Shamna et al. ${ }^{7}$

On Naranjo scale, the causality assessment of $64 \%$ of reactions was Probable, while a study done by Mandaviet al reported $88.6 \%$ as probable. ${ }^{8,9}$

Most notorious drugs to cause adverse drug reactions were anticancer drugs since the patients were on multiple drugs.

\section{Conclusion}

Pharmacovigilance programs should be publicised to sensitize the health-care workers about monitoring and documentation of ADRs. This can curtail many untoward reactions in patient.

\section{Acknowledgement}

We would like to thank the Adverse drug Monitoring Center (AMC), DRPGMC Tanda, under IPC-NCC, Ghaziabad, MOHF, Government of India, under the PvPI for providing us data.

\section{References}

1. Gershanik J, Boecler B, Ensley H, McCloskey S, George $\mathrm{W}$. The gasping syndrome and benzyl alcohol poisoning. Engl J Med 1982;307(22):1384-8.

2. Lihite RJ, Lahkar M. An update on the Pharma covigilance Programme of India. Front Pharmacol 2015;6:194.

3. Naranjo CA, Busto U, Sellers EM, Sandor P, Ruiz I, Roberts EA, et al. A method for estimating the probability of adverse drug reactions. Clin Pharmacol Ther 1981;30(2):239-45.

4. Saravanan SS, Kavitha P, Ponnuswamy TK. Patterns of adverse drug reactions in the medical intensive care unit of an Indian tertiary care hospital. Int J Pharm Biol Arch 2014;5(3):64-8.

5. Kathiria JM, Sattigeri BM, Desai PM, Patel SP. A study of adverse drug reactions in patients admitted to intensive care unit of a tertiary care teaching rural hospita. Int J Pharm PharmSci 2013;5(1):160-3.

6. Rademaker M. Do women have more adverse drug reactions? Am J Clin Dermatol 2001;2(6):349-51.

7. Shamna M, Dilip C, Ajmal M, Linu Mohan P, Shinu C, Jafer CP, et al. A prospective study on Adverse Drug Reactions of antibiotics in a tertiary care hospital. Saudi Pharm J 2014;22(4):303-8.

8. Stavreva G, Pendicheva D, Pandurska A, Marev R. Detection of adverse drug reactions to antimicrobial drugs in hospitalized patients. Trakia J Sci 2008;6(1):7-9.

9. Mandavi, Dcruz S, Sachdev A, Tiwari P. Adverse drug reactions $\&$ their risk factors among Indian ambulatory elderly patients. Indian J Med Res 2012;136:404-10. 